\title{
Review of depot aripiprazole for schizophrenia
}

\author{
This article was published in the following Dove Press journal: \\ Patient Preference and Adherence \\ 12 November 2013 \\ Number of times this article has been viewed
}

\section{Farha Bilal Motiwala \\ Kim Stasia Siscoe \\ Rif S El-Mallakh}

Mood Disorders Research Program, Department of Psychiatry and Behavioral Sciences, University of Louisville School of Medicine, Louisville, KY, USA
Correspondence: Rif S El-Mallakh Mood Disorders Research Program, Department of Psychiatry and Behavioral Sciences, University of Louisville School of Medicine, MedCenter One, 50I East Broadway, Suite 340, Louisville, KY 40202, USA

Tel + I 502852 I I 24

Fax + I 5028525098

Email rselma0।@louisville.edu
Abstract: Improving outcomes in schizophrenia generally requires an improvement in medication adherence. One of the most effective interventions to improve adherence is the use of depot formulations of antipsychotic medications. A new depot aripiprazole formulation for the treatment of schizophrenia will be available soon. A review of all publically available information on depot aripiprazole as of November 2012 was performed. One peer-reviewed study on depot aripiprazole is published, and the remainder of the data were presented at international scientific meetings. Depot aripiprazole appears to be both safe and effective in the long-term treatment of schizophrenia.

Keywords: aripiprazole, schizophrenia, depot, long-acting injectable, psychosis, treatment

\section{Introduction}

Schizophrenia is a chronic and debilitating mental illness that requires lifetime management with medication to prevent decompensation and worsening of symptoms over time. Nonadherence with antipsychotic medication is associated with an overall poor prognosis. ${ }^{1-3}$ In addition to increased likelihood of recurrence of psychosis and rehospitalization, ${ }^{1,4,5}$ patients can experience worsened medical outcomes. ${ }^{6}$ Across both first-generation and second-generation antipsychotics, poor adherence is observed in many patients, with estimates of $28.8 \%-80 \%$ of patients being nonadherent with antipsychotic medication. ${ }^{7-10}$ Adherence is minimally better with oral second-generation antipsychotics (SGA) at $54.9 \%$ versus $50.1 \%$ for first-generation antipsychotics. ${ }^{11}$ Several factors lead to nonadherence, including poor insight, coexistent substancerelated issues, lack of education and awareness about the illness, stigma, unrealistic expectation for treatment response, adverse consequences of medications, low rate of acceptance of illness, and cognitive disorders. ${ }^{12-19}$ Many interventions have been tried to improve adherence. These include specific treatments such as electronic reminders, ${ }^{20}$ interventions that are tailored to the patient, ${ }^{21}$ focusing on patient insight, ${ }^{22,23}$ improving oversight by friends or relatives, ${ }^{5,24,25}$ or focusing on the relationship between the patient and provider. ${ }^{14-16}$ From a medication stand point, long-acting injectable (LAI) antipsychotics are frequently seen as an intervention to improve adherence. ${ }^{9}$

LAIs are in reality a form of supervision of medication administration. Forced treatment, in and of itself, does not improve outcome; ${ }^{26}$ however, supervised administration of medication in a trusting relationship can be very effective. In this regard, LAI are nearly universally associated with better outcome when compared with oral medications. ${ }^{27-29}$ 
Treatment of schizophrenia patients with depot injections is infrequent worldwide, constituting less than $20 \%$ of outpatients. Its use is more common in Denmark, the United Kingdom, and Sweden, while the United States and France have lower rates..$^{30,31}$ Less than one third of psychiatrists offer a depot option to their patients. ${ }^{32}$ The leading reason for this is the erroneous impression that patients are adherent with oral medication. ${ }^{32,33}$ The hesitancy to suggest depot medications is in opposition to the data that patients and their families generally have positive attitudes towards depot formulations, ${ }^{34-37}$ with many patients preferring the depot form. ${ }^{34}$

SGAs are generally preferred by clinicians because of better adherence and better psychosocial outcomes. ${ }^{19,38}$ While the superiority of SGAs has recently been challenged, ${ }^{39,40}$ they remain the preferred class of antipsychotic medications in the management of schizophrenia. ${ }^{41}$ Furthermore, despite their upfront higher cost, SGAs can offer cost savings to the health care system. For example, LAI risperidone saves over US $\$ 8,000 /$ patient annually in health care costs compared with LAI haloperidol. ${ }^{42,43}$

Among the SGAs, aripiprazole is considered atypical. Aripiprazole has a unique receptor profile as a partial agonist at the D2 receptor, resulting in fewer extrapyramidal symptoms while still controlling psychotic symptoms. ${ }^{44-46}$ It is also a partial agonist at the $5 \mathrm{HT}_{1 \mathrm{~A}}$ receptor and a $5 \mathrm{HT}_{2 \mathrm{~A}}$ antagonist. ${ }^{47,48}$ It is the only SGA with greater affinity at the $\mathrm{D} 2$ receptor compared with the $5 \mathrm{HT}_{2 \mathrm{~A}}$ receptor. In addition, aripiprazole is thought to have a favorable metabolic profile with reduced weight gain and reduced propensity to increase lipids compared with other SGAs. ${ }^{49}$ This results in significant reductions in the incidence of diabetes and myocardial infarctions, and consequent savings in cost of total health care (nearly $£ 4$ million/year in the United Kingdom), compared with standard of care treatments..$^{50}$ Currently, aripiprazole is available as an oral daily medication (also available are oral disintegrating tablets, liquid), as well as a rapidly acting intramuscular injectable for management of acute agitation associated with schizophrenia. ${ }^{51}$ Oral aripiprazole offers good tolerability and efficacy for chronic use $\mathrm{e}^{52,53}$ and thus a depot formulation would be expected to be desirable.

\section{Materials and methods}

Searches utilizing the search terms "aripiprazole", "depot", and/or "long-acting injectable" in PubMed and Google Scholar resulted in one paper that dealt with LAI aripiprazole. There were no other studies, including no case reports, case series, open studies, or preclinical studies. The one published study was a placebo-controlled, randomized, multiple-site study examining the utility and safety of LAI aripiprazole in relapse prevention in stable patients with schizophrenia. To supplement this one study, data that had been presented previously in poster form at peer-reviewed international professional meetings as of November 2012 were obtained from Otsuka Pharmaceuticals, and included.

\section{Results}

Aripiprazole was studied for use as a monthly intramuscular injection. The depot formulation is a lyophilized (cryodesiccated or freeze-dried) powder reconstituted with water, which is then injected into a large muscle. No modification of the aripiprazole molecule was done to develop the long-acting formulation of this medication. ${ }^{46}$ With steady absorption from the muscle, plasma levels reach levels similar to that of the hypothesized therapeutic doses of oral aripiprazole. ${ }^{54}$ It took approximately 2 months for intramuscular aripiprazole to reach steady state, but mean plasma levels were similar to oral aripiprazole administration within 2 weeks. ${ }^{54}$ The half-life of LAI aripiprazole is 46.5 days for a $400 \mathrm{mg}$ dose and 29.9 days for a $300 \mathrm{mg}$ dose,${ }^{54}$ allowing for a once-monthly injection.

One randomized, controlled study of LAI aripiprazole has been published. ${ }^{46}$ This study was conducted in 108 centers located throughout the world from July 2008 through February 2011. Subjects had to have schizophrenia and be stable for 4 weeks on oral aripiprazole to qualify for the study. Stability was defined as being an outpatient, having a Positive and Negative Symptom Scale (PANSS) score of $<81$, no specific psychotic symptom with a PANSS $>4$, a Clinical Global Impression score $\leq 4$, and absence of significant suicidality. ${ }^{46}$

Of 1,025 subjects who underwent screening, 843 qualified for the study. Once all patients were converted to oral aripiprazole via cross titration, patients were stabilized on open-label oral aripiprazole monotherapy 10-30 mg daily for 4 consecutive weeks. Patients who met the criteria for stabilization were then stabilized on open-label LAI aripiprazole. Concurrent with the first injection of LAI aripiprazole, oral aripiprazole was continued for 2 weeks. Subjects who remained stable consistently for at least 3 months on depot aripiprazole were randomized into the study in a 2:1 active to placebo ratio, with a total of 403 patients reaching the double-blind randomization phase. ${ }^{46}$ Injection of LAI aripiprazole was started at $400 \mathrm{mg}$ intramuscularly independent of oral dose, with the potential to reduce the dose to $300 \mathrm{mg}$ intramuscularly if patients were experiencing adverse effects. During the double-blind phase, $96.3 \%$ of the patients remained on $400 \mathrm{mg}$. 
The study was designed to go for 52 weeks, with two predetermined interim analyses, the first after a total of 64 subjects met criteria for recurrence. The interim analysis demonstrated that the active drug was significantly different from placebo, without any overt safety concerns, and the study was stopped early with $58.8 \%$ of subjects discontinuing due to sponsor discontinuation. ${ }^{46}$

The primary outcome in the study was recurrence or "relapse", that was defined in one of four ways: worsening as defined by a score $\geq 5$ on the Clinical Global Impression scale, ${ }^{55}$ a collective increase of 4 points in core psychotic symptoms, or an individual increase of two or more in these core psychotic symptoms (on the PANSS ${ }^{56}$ including disorganized thoughts, paranoid behavior, hallucinations, or bizarre thoughts/behavior), aggravation of psychotic illness leading to hospital admission, or destructive injury to self, others, or property.

The mean age of the subjects was 40.1 years and 41.7 years for the aripiprazole and placebo groups, respectively. Aripiprazole depot intramuscular injection significantly extended the duration to relapse/recurrence (Figure 1). Of the 80 subjects who experienced a recurrence, 27 were receiving aripiprazole (or $10 \%$ of 269 on aripiprazole), and 53 were on placebo (or $39.6 \%$ or 134 subjects on placebo).$^{46}$ The hazard ratio was calculated at 5.03 (confidence interval 3.15-8.02), meaning placebo-treated subjects were over five times more likely to experience a recurrence ( $>500 \%$ increased risk). The duration to termination of treatment as a result of all causes except sponsor-induced termination of the study was significantly lengthened with use of aripiprazole depot, with a termination rate of $24.9 \%$ as compared with placebo treatment, which had a $54.5 \%$ termination rate.

The actual change in symptomatic level was significantly greater in placebo-treated subjects prior to withdrawal from the study (Figure 2). Placebo-treated subjects experienced a mean 11.6 point increase in total PANSS score, compared with LAI aripiprazole-treated subjects with a mean 1.4 point increase $(P=0.0001)$. This difference in PANNS score between the two groups was evident by the second week and persisted throughout the study (Figure 2). Aggression was less common in aripiprazole-treated subjects $(3.7 \%, \mathrm{n}=1 / 27)$ than in placebo-treated subjects $(7.5 \%, n=4 / 53)$.

Adverse events were relatively uncommon in both activetreated and placebo-treated subjects (Table 1). Adverse events occurring during the initial LAI aripiprazole stabilization period were very similar to those shown in Table 1 of the Kane paper on aripiprazole-treated subjects. ${ }^{46}$ Nearly all adverse events were mild to moderate. The only severe adverse events dealt with worsening psychosis, which involved $2.2 \%$ of aripiprazole-treated subjects and $4.5 \%$ of placebo-treated subjects. Adverse events led to termination in 7.1\% (19 of 269) of LAI aripiprazole-treated subjects and $13.4 \%$ (18 of 134) of placebo-treated individuals. ${ }^{46,57}$

Pain at the injection site was uncommon (Table 1), and severity was measured by a 100 point visual analog scale; the actual severity was 5.1 , declining to 4.0 in aripiprazoletreated subjects, and 5.1 declining to 4.9 in the placebo group. ${ }^{46,57}$ Extrapyramidal symptoms were measured using the Abnormal Involuntary Movement Scale, ${ }^{58}$ parkinsonism was measured with the Simpson Angus Scale, ${ }^{59}$ and akathisia

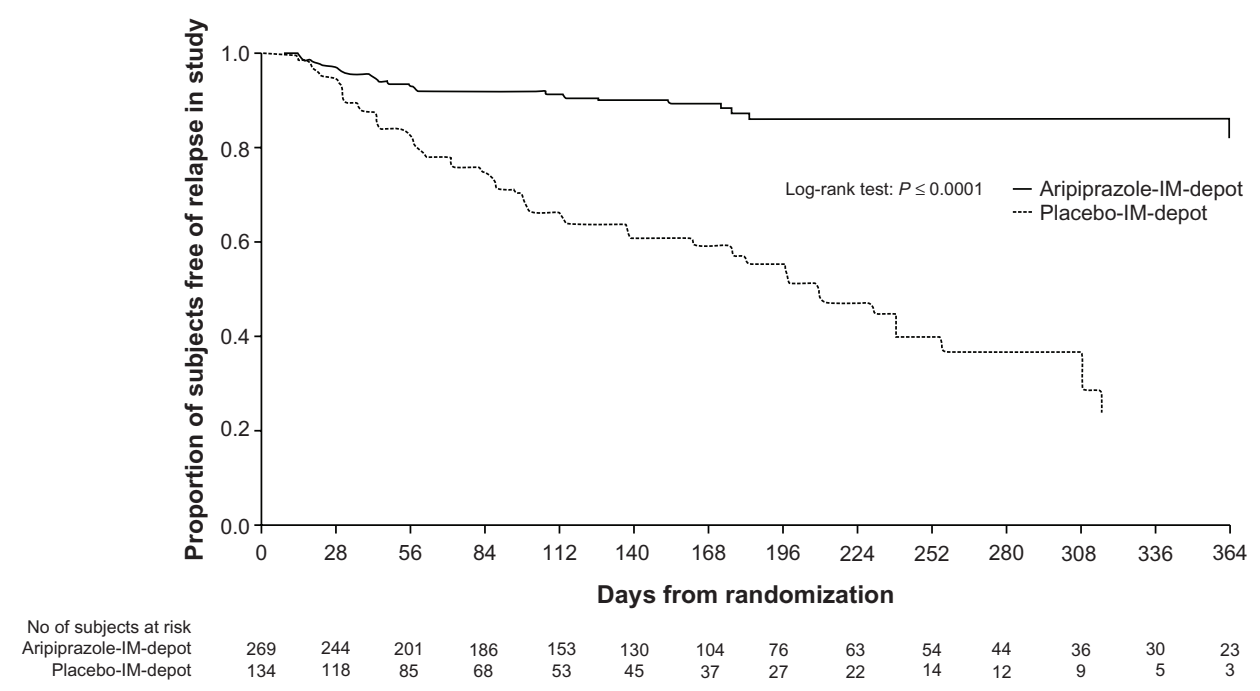

Figure I Time to discontinuation from the study for "impending relapse" (see text for definition) in depot aripiprazole-treated and vehicle-treated subjects. Reprinted with permission from Kane JM, Sanchez R, Perry PP, et al. Aripiprazole intramuscular depot as maintenance treatment in patients with schizophrenia: a 52-week, multicenter, randomized, double-blind, placebo-controlled study. J Clin Psychiatry. 2012;73:6I7-624. @ 20I2, Physicians Postgraduate Press. ${ }^{46}$ Abbreviation: IM, intramuscular. 


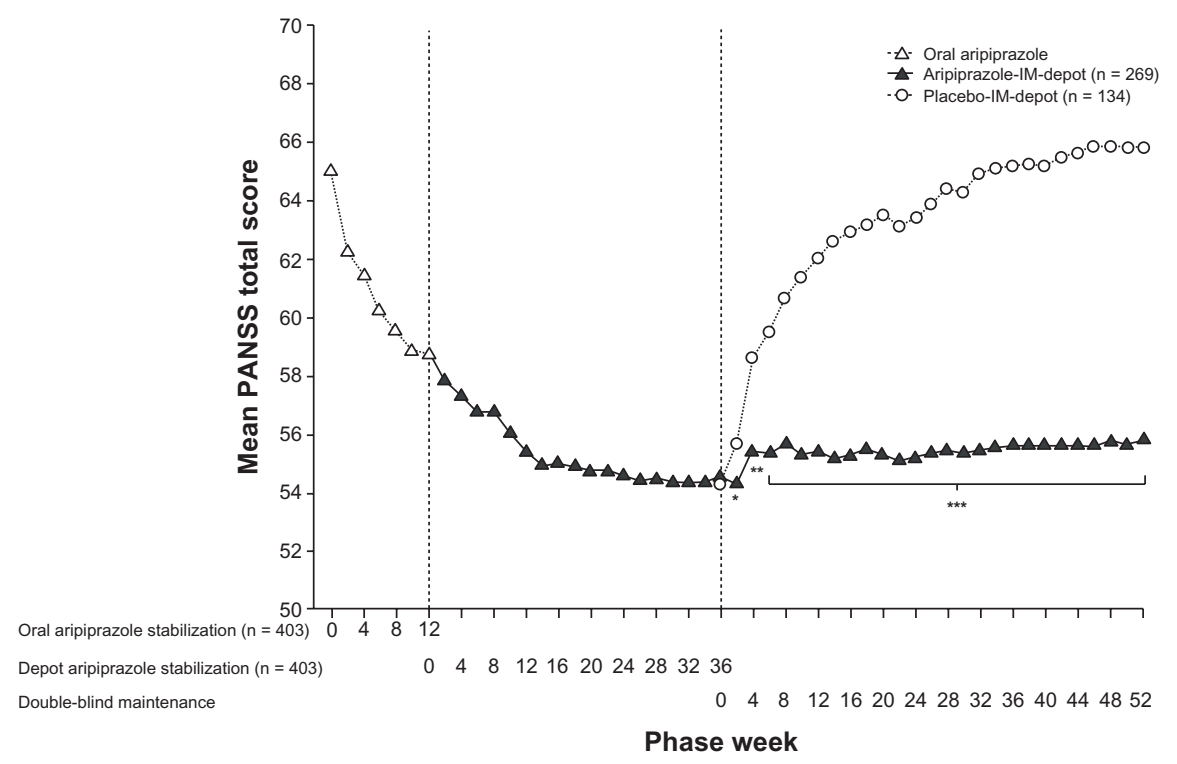

Figure 2 Total PANSS score over the course of the study. After randomization to placebo or active LAI aripiprazole, the mean PANSS score returned to baseline in the placebo-treated patients, but remained stable in the aripiprazole-treated patients (means are presented as last observation carried forward).

Reprinted with permission from Kane JM, Sanchez R, Perry PP, et al. Aripiprazole intramuscular depot as maintenance treatment in patients with schizophrenia: a 52week, multicenter, randomized, double-blind, placebo-controlled study. J Clin Psychiatry. 2012;73:617-624. @ 20I2, Physicians Postgraduate Press. ${ }^{46}$

Abbreviations: IM, intramuscular; PANSS, Positive and Negative Symptoms Scale.

with the Barnes scale. ${ }^{60}$ Extrapyramidal symptoms were reported more in patients receiving active intramuscular aripiprazole $(14.9 \%)$ than in patients receiving placebo $(9.7 \%)$. Measured akathisia was not different between the groups (5.6\% and 6.0\%, for the patients on aripiprazole depot injection and placebo, respectively). Parkinsonism with tremor was the most commonly reported adverse event at $8.2 \%$ for subjects in the aripiprazole group in comparison with $3.0 \%$ in the placebo group. However, no significant differences

Table I Common adverse events occurring in the double-blind portion of the study

\begin{tabular}{llll}
\hline Adverse event & \multicolumn{1}{l}{ LAl aripiprazole (\%) } & & Placebo n (\%) \\
\cline { 2 - 2 } & $\mathbf{( n = 2 6 9 )}$ & & $\mathbf{( n = 1 3 4 )}$ \\
\hline Insomnia & $27(10.0)$ & $12(9.0)$ \\
Increased weight & $26(9.7)$ & $13(9.7)$ \\
Anxiety & $16(5.9)$ & $10(7.5)$ \\
Headache & $16(5.9)$ & $7(5.2)$ \\
Tremor & $16(5.9)$ & $2(1.5)$ \\
Akathisia & $15(5.6)$ & $8(6.0)$ \\
Nasopharyngitis & $10(3.7)$ & $7(5.2)$ \\
Worsening psychosis & $8(3.0)$ & $9(6.7)$ \\
Injection site pain & $8(3.0)$ & $5(3.7)$ \\
Any adverse events & $170(63.2)$ & $83(6 I .9)$ \\
\hline
\end{tabular}

Notes: Modified with permission Kane JM, Sanchez R, Perry PP, et al. Aripiprazole intramuscular depot as maintenance treatment in patients with schizophrenia: a 52-week, multicenter, randomized, double-blind, placebo-controlled study. J Clin Psychiatry. 2012;73:617-624. (c) 2012, Physicians Postgraduate Press ${ }^{46}$ and data from Fleischhacker et al. ${ }^{57}$

Abbreviation: LAI, long-acting injectable. were observed in any of the three extrapyramidal symptom scales between LAI aripiprazole and placebo.

Weight change was not different between the two groups after randomization, with the LAI aripiprazole patients losing a mean of $0.2 \mathrm{~kg}$, and the placebo-treated patients losing a mean of $0.4 \mathrm{~kg}(P=0.812)$. A clinically relevant increase in weight ( $>7 \%$ from baseline) was experienced by $6.4 \%$ of LAI aripiprazole-treated subjects, and $5.2 \%$ of placebotreated subjects. ${ }^{46,57}$

Two people died during the study, one due to coronary artery insufficiency during the intramuscular aripiprazole stabilization period and one due to pancreatic carcinoma during the double-blind treatment phase. ${ }^{46}$ Four adverse events associated with suicide were reported during double-blind treatment. Three individuals $(1.1 \%)$ experienced suicidal ideation, and a fourth $(0.4 \%)$ attempted suicide while receiving LAI aripiprazole. ${ }^{46}$

In addition to having significant efficacy and a very good safety profile, LAI aripiprazole was also well received by the patients. Acceptance, as measured by the Drug Attitude Inventory, ${ }^{61}$ was quite high (score 21.1 versus placebo at 22.2). ${ }^{62}$ This was reflected in a Medication Adherence Questionnaire $^{63}$ score of 0 to 1, and a final Patient Satisfaction with Medication Questionnaire score of $86.2 \%$ in aripiprazole-treated patients versus $85.7 \%$ in placebo-treated subjects. ${ }^{62}$ Function, as measured by the Personal and Social 
Performance scale, ${ }^{64}$ did not change compared with baseline in aripiprazole-treated patients, but declined significantly in placebo-treated patients. ${ }^{65}$

How would clinicians use, and what could one expect using, aripiprazole intramuscular depot injection in clinical practice? Based on this study, an oral trial and cross taper of the medication should be done prior to initiation of a monthly injection to stabilize symptoms. For the first 2 weeks of the initial depot injection, oral aripiprazole should be continued to allow adequate time for the intramuscular medication to reach adequate plasma concentrations, which we know can take approximately 6-12 days. ${ }^{46,57}$ Injections can then be given monthly without any oral supplementation of the medication based on the half-life of the depot formulation of 46.5 days and 29.9 days for the $400 \mathrm{mg}$ and $300 \mathrm{mg}$ doses, respectively. Providers could expect to see a similar effect on PANSS reduction as the oral formulation and a low rate of recurrence. ${ }^{65}$ Providers could also expect a good patient attitude towards this medication since patients assigned to the LAI formulation were very satisfied with their treatment.

Overall, these data suggest that LAI aripiprazole will be a useful clinical tool when it becomes available. Aripiprazole has many unique and beneficial actions, and the initial data suggest that these will be preserved in the LAI formulation, with the additional benefit of guaranteed medication administration.

\section{Disclosure}

The authors report no conflicts of interest in this work.

\section{References}

1. Caseiro O, Pérez-Iglesias R, Mata I, et al. Predicting relapse after a first episode of non-affective psychosis: a three-year follow-up study. J Psychiatr Res. 2012;46:1099-1105.

2. Leucht S, Heres S. Epidemiology, clinical consequences, and psychosocial treatment of nonadherence in schizophrenia. J Clin Psychiatry. 2006;67 Suppl 5:3-8.

3. Sun SX, Liu GG, Christensen DB, Fu AZ. Review and analysis of hospitalization costs associated with antipsychotic nonadherence in the treatment of schizophrenia in the United States. Curr Med Res Opin. 2007;23:2305-2312.

4. Jaeger S, Pfiffner C, Weiser P, et al. Adherence styles of schizophrenia patients identified by a latent class analysis of the Medication Adherence Rating Scale (MARS): a six-month follow-up study. Psychiatry Res. 2012;200:83-88.

5. Farley JF, Hansen RA, Yu-Isenberg KS, Maciejewski ML. Antipsychotic adherence and its correlation to health outcomes for chronic comorbid conditions. Prim Care Companion CNS Disord. 2012;14:piiPCC.11m01324.

6. Kopelowicz A, Zarate R, Wallace CJ, Liberman RP, Lopez SR, Mintz J. The ability of multifamily groups to improve treatment adherence in Mexican Americans with schizophrenia. Arch Gen Psychiatry. 2012;69: 265-273.
7. Lacro JP, Dunn LB, Dolder CR, Leckband SG, Jeste DV. Prevalence of and risk factors for medication non adherence in patients with schizophrenia: a comprehensive review of recent literature. J Clin Psychiatry. 2002;63:892-909.

8. Byerly M, Fisher R, Whatley K, et al. A comparison of electronic monitoring vs clinician rating of antipsychotic adherence in outpatients with schizophrenia. Psychiatry Res. 2005;133:129-133.

9. Novick D, Haro JM, Suarez D, Perez V, Dittmann RW, Haddad PM. Predictors and clinical consequences of non-adherence with antipsychotic medication in the outpatient treatment of schizophrenia. Psychiatry Res. 2010;176:109-113.

10. Alene M, Wiese MD, Angamo MT, Bajorek BV, Yesuf EA, Wabe NT. Adherence to medication for the treatment of psychosis: rates and risk factors in an Ethiopian population. BMC Clin Pharmacol. 2012;12:10.

11. Dolder CR, Lacro JP, Dunn LB, Jeste DV. Antipsychotic medication adherence: is there a difference between typical and atypical agents. Am J Psychiatry. 2002;159:103-108.

12. Fenton WS, Byler CR, Heinssen RK. Determinants of medication compliance in schizophrenia: empirical and clinical findings. Schizophr Bull. 1997;23:637-651.

13. Day JC, Bentall RP, Roberts C, et al. Attitudes toward antipsychotic medication: the impact of clinical variables and relationships with health professionals. Arch Gen Psychiatry. 2005;62:717-724.

14. McCabe R, Bullenkamp J, Hansson L, et al. The therapeutic relationship and adherence to antipsychotic medication in schizophrenia. PLoS One. 2012;7:e36080.

15. Misdrahi D, Petit M, Blanc O, Bayle F, Llorca PM. The influence of therapeutic alliance and insight on medication adherence in schizophrenia. Nord J Psychiatry. 2012;66:49-54.

16. McCann TV, Boardman G, Clark E, Lu S. Risk profiles for non-adherence to antipsychotic medications. $J$ Psychiatr Ment Health Nurs. 2008;15:622-629.

17. de Haan L, van Amelsvoort T, Dingemans P, Linszen D. Risk factors for medication non-adherence in patients with first episode schizophrenia and related disorders: a prospective five year follow-up. Pharmacopsychiatry. 2007;40:264-268.

18. Miller R, Ream G, McCormack J, Gunduz-Bruce H, Sevy S, Robinson D. A prospective study of cannabis use as a risk factor for non-adherence and treatment dropout in first-episode schizophrenia. Schizophr Res. 2009;113:138-144.

19. Ascher-Svanum H, Zhu B, Faries D, Landbloom R, Swartz M, Swanson J. Time to discontinuation of atypical versus typical antipsychotics in the naturalistic treatment of schizophrenia. $B M C$ Psychiatry. 2006;6:8.

20. Granholm E, Ben-Zeev D, Link PC, Bradshaw KR, Holden JL. Mobile Assessment and Treatment for Schizophrenia (MATS): a pilot trial of an interactive text-messaging intervention for medication adherence, socialization, and auditory hallucinations. Schizophr Bull. 2012;38: 414-425.

21. Staring AB, Van der Gaag M, Koopmans GT, et al. Treatment adherence therapy in people with psychotic disorders: randomised controlled trial. Br J Psychiatry. 2010;197:448-455.

22. Schennach R, Meyer S, Seemüller F, et al. Insight in schizophreniacourse and predictors during the acute treatment phase of patients suffering from a schizophrenia spectrum disorder. Eur Psychiatry. 2012;27:625-633.

23. Trevisi M, Talamo A, Bandinelli PL, et al. Insight and awareness as related to psychopathology and cognition. Psychopathology. 2012;45: 235-243.

24. Farooq S, Nazar Z, Irfan M, et al. Schizophrenia medication adherence in a resource-poor setting: randomised controlled trial of supervised treatment in out-patients for schizophrenia (STOPS). Br J Psychiatry. 2011;199:467-472.

25. Glick ID, Stekoll AH, Hays S. The role of the family and improvement in treatment maintenance, adherence, and outcome for schizophrenia. J Clin Psychopharmacol. 2011;31:82-85. 
26. Spinzy Y, Israel K. Assessing the effect of compulsory ambulatory treatment orders on the time lapse out of hospitalization for patients suffering from schizophrenia. Harefuah. 2012;151:155-158. Hebrew.

27. Bartzokis G, Lu PH, Amar CP, et al. Long acting injection versus oral risperidone in first-episode schizophrenia: differential impact on white matter myelination trajectory. Schizophr Res. 2011;132:35-41.

28. Tiihonen J, Haukka J, Taylor M, Haddad PM, Patel MX, Korhonen P. A nationwide cohort study of oral and depot antipsychotics after first hospitalization for schizophrenia. Am J Psychiatry. 2011;168:603-609.

29. Zhornitsky S, Stip E. Oral versus long-acting injectable antipsychotics in the treatment of schizophrenia and special populations at risk for treatment nonadherence: a systematic review. Schizophr Res Treatment. 2012;2012:407171.

30. Dencker S, Axelson R. Optimising the use of depot antipsychotics. CNS Drugs. 1996;6:367-381.

31. West JC, Marcus SC, Wilk J, Countis LM, Regier DA, Olfson M. Use of depot antipsychotic medications for medication nonadherence in schizophrenia. Schizophr Bull. 2008;34:995-1001.

32. Heres S, Hamann J, Kissling W, Leucht S. Attitudes of psychiatrists toward antipsychotic depot medication. J Clin Psychiatry. 2006;67:1948-1953.

33. Clayton CD, Veach J, Macfadden W, Haskins J, Docherty JP, Lindenmayer JP. Assessment of clinician awareness of nonadherence using a new structured rating scale. J Psychiatr Pract. 2010;16:164-169.

34. Walburn J, Gray R, Gournay K, Quraishi S, David AS. Systematic review of patient and nurse attitudes to depot antipsychotic medication. Br J Psychiatry. 2001;179:300-307.

35. Heres S, Schimtz FS, Leucht S, Pajonk FG. The attitudes of patients towards depot treatment. Int Clin Psychopharmacol. 2007;22:275-282.

36. Patel MX, De Zoysa N, Bernadt M, David A. Depot and oral antipsychotics: patient preferences and attitudes are not the same thing. J Psychopharmacol. 2009;23:789-796.

37. Jaeger M, Rossler W. Attitudes towards long-acting depot antipsychotics: a survey of patients, relatives and psychiatrists. Psychiatry Res. 2010;175:58-62.

38. Fujimaki K, Takahashi T, Morinobu S. Association of typical versus atypical antipsychotics with symptoms and quality of life in schizophrenia. PLoS One. 2012;7:e37087.

39. Stargardt T, Edel MA, Ebert A, Busse R, Juckel G, Gericke CA. Effectiveness and cost of atypical versus typical antipsychotic treatment in a nationwide cohort of patients with schizophrenia in Germany. JClin Psychopharmacol. 2012;32:602-607.

40. Stargardt T, Weinbrenner S, Busse R, Juckel G, Gericke CA. Effectiveness and cost of atypical versus typical antipsychotic treatment for schizophrenia in routine care. $J$ Ment Health Policy Econ. 2008;11:89-97.

41. Sankaranarayanan J, Puumala SE. Antipsychotic use at adult ambulatory care visits by patients with mental health disorders in the United States, 1996-2003: national estimates and associated factors. Clin Ther. 2007; 29:723-741

42. Edwards NC, Locklear JC, Rupnow MF, Diamond RJ. Cost effectiveness of long-acting risperidone injection versus alternative antipsychotic agents in patients with schizophrenia in the USA. Pharmacoeconomics. 2005;23 Suppl 1:75-89.

43. Yang YK, Tarn YH, Wang TY, et al. Pharmacoeconomic evaluation of schizophrenia in Taiwan: model comparison of long-acting risperidone versus olanzapine versus depot haloperidol based on estimated costs. Psychiatry Clin Neurosci. 2005;59:385-394.

44. Burris KD, Molski TF, Xu C, et al. Aripiprazole, a novel antipsychotic, is a high affinity partial agonist at human dopamine D2 receptors. J Pharmacol Exp Ther. 2002;302:381-389.

45. Shapiro DA, Renock S, Arrington E, et al. Aripiprazole, a novel atypical antipsychotic drug with a unique and robust pharmacology. Neuropsychopharmacology. 2003;28:1400-1411.
46. Kane JM, Sanchez R, Perry PP, et al. Aripiprazole intramuscular depot as maintenance treatment in patients with schizophrenia: a 52-week, multicenter, randomized, double-blind, placebo-controlled study. J Clin Psychiatry. 2012;73:617-624.

47. Jordan S, Koprivica V, Chen R, Tottori K, Kikuchi T, Altar CA. The antipsychotic aripiprazole is a potent, partial agonist at the human 5-HT ${ }_{1 \mathrm{~A}}$ receptor. Eur J Pharmacol. 2002;441:137-140.

48. Stark AD, Jordan S, Allers KA, et al. Interaction of the novel antipsychotic aripiprazole with $5-\mathrm{HT}_{1 \mathrm{~A}}$ and $5-\mathrm{HT}_{2 \mathrm{~A}}$ receptors: functional receptor-binding and in vivo electrophysiological studies. Psychopharmacology (Berl). 2007;190:373-382.

49. Rummel-Kluge C, Komossa K, Schwarz S, et al. Head-to-head comparisons of metabolic side effects of second generation antipsychotics in the treatment of schizophrenia: a systematic review and meta-analysis. Schizophr Res. 2010;123:225-233.

50. Barnett AH, Millar HL, Loze JY, et al. UK cost-consequence analysis of aripiprazole in schizophrenia: diabetes and coronary heart disease risk projections (STAR study). Eur Arch Psychiatry Clin Neurosci. 2009;259:239-247.

51. Andrezina R, Josiassen RC, Marcus RN, et al. Intramuscular aripiprazole for the treatment of acute agitation in patients with schizophrenia or schizoaffective disorder: a double-blind, placebo-controlled comparison with intramuscular haloperidol. Psychopharmacology (Berl). 2006;188:281-292.

52. Kasper S, Lerman MN, McQuade RD, et al. Efficacy and safety of aripiprazole vs haloperidol for long-term maintenance treatment following acute relapse of schizophrenia. Int J Neuropsychopharmacol. 2003;6:325-337.

53. Pigott TA, Carson WH, Saha AR, Torbeyns AF, Stock EG, Ingenito GG; Aripiprazole Study Group. Aripiprazole for the prevention of relapse in stabilized patients with chronic schizophrenia: a placebo-controlled 26-week study. J Clin Psychiatry. 2003;64:1048-1056.

54. Fleischhacker WW, Kane JM, Sanchez R, et al. A pharmacokinetic study of once- monthly aripiprazole extended release injectable suspension (ARI- ERIS) in adult patients with schizophrenia. Presented at the 164th Annual Meeting of the American Psychiatric Association, May 14-16, 2011, Honolulu, HI.

55. Guy W. ECDEU Assessment Manual for PsychopharmacologyRevised. Rockville, MD: US Department of Health Services; 1976.

56. Kay SR, Fiszbein A, Opler LA. The Positive and Negative Syndrome Scale (PANSS) for schizophrenia. Schizophr Bull. 1987;13: 261-276.

57. Fleischhacker WW, Sanchez R, Perry P, et al. Long-term safety and tolerability of once-monthly aripiprazole-intramuscular-depot for maintenance treatment in schizophrenia. Presented at the 165th Annual Meeting of the American Psychiatric Association, Philadelphia, PA, May $5-9,2012$.

58. Guy W. ECDEU Assessment Manual for Psychopharmacology. Rockville, MD, US Department of Health, Education and Welfare, Public Health Service, Alcohol, Drug Abuse and Mental Health Administration, NIMH Psychopharmacology Research Branch, Division of Extramural Research Programs. 1976:534-537.

59. Simpson GM, Angus JW. A rating scale for extrapyramidal side effects. Acta Psychiatr Scand Suppl. 1970;45:11-19.

60. Barnes TR. A rating scale for drug-induced akathisia. Br J Psychiatry. 1989;154:672-676.

61. Hogan TP, Awad AG, Eastwood R. A self-report scale predictive of drug compliance in schizophrenics: reliability and discriminative validity. Psychol Med. 1983;13:177-183.

62. Sanchez R, Johnson B, Jin M, et al. Patient-reported outcomes with aripiprazole-intramuscular-depot for long-term maintenance treatment in schizophrenia. Presented at the 165th Annual Meeting of the American Psychiatric Association, Philadelphia, PA, May $5-9,2012$. 
63. Thompson K, Kulkarni J, Sergejew AA. Reliability and validity of a new Medication Adherence Rating Scale (MARS) for the psychoses. Schizophr Res. 2000;42:241-247.

64. Nafees B, van Hanswijck de Jonge P, et al. Reliability and validity of the Personal and Social Performance scale in patients with schizophrenia. Schizophr Res. 2012;140:71-76.
65. Carson WH, Perry P, Sanchez R, et al. Effects of a long acting injectable formulation of aripiprazole on secondary efficacy outcomes in maintenance treatment of schizophrenia. Presented at the 165th Annual Meeting of the American Psychiatric Association, Philadelphia, PA, May 5-9, 2012.

\section{Publish your work in this journal}

Patient Preference and Adherence is an international, peer-reviewed, open access journal focusing on the growing importance of patient preference and adherence throughout the therapeutic continuum. Patient satisfaction, acceptability, quality of life, compliance, persistence and their role in developing new therapeutic modalities and compounds to optimize clinical outcomes for existing disease states are major areas of interest. This journal has been accepted for indexing on PubMed Central. The manuscript management system is completely online and includes a very quick and fair peer-review system. Visit http://www.dovepress.com/ testimonials.php to read real quotes from published authors.

Submit your manuscript here: http://www.dovepress.com/patient-preference-and-adherence-journal 